\title{
Predictors of Assertive and Nonassertive Styles of Self-Defense Behavior During a Lab-Based Sexual Assault Scenario
}

\author{
RaeAnn E. Anderson \\ University of North Dakota, raeann.anderson@UND.edu \\ Shawn P. Cahill \\ Kristin E. Silver \\ Douglas D. Delahanty
}

\section{How does access to this work benefit you? Let us know!}

Follow this and additional works at: https://commons.und.edu/psych-fac

\section{Recommended Citation}

RaeAnn E. Anderson, Shawn P. Cahill, Kristin E. Silver, et al.. "Predictors of Assertive and Nonassertive Styles of Self-Defense Behavior During a Lab-Based Sexual Assault Scenario" (2019). Psychology Faculty Publications. 9.

https://commons.und.edu/psych-fac/9 
PREDICTORS OF ASSERTIVE AND NON-ASSERTIVE STYLES OF SELF-DEFENSE BEHAVIOR DURING A LAB-BASED SEXUAL ASSAULT SCENARIO

\author{
RaeAnn E. Anderson ${ }^{1,2,3 *}$ Shawn P. Cahill ${ }^{2}$, Kristin E. Silver ${ }^{4}$, Douglas L. Delahanty ${ }^{1}$ \\ ${ }^{1 .}$ Kent State University, Kent, $\mathrm{OH}$ \\ 2. University of Wisconsin-Milwaukee, Milwaukee, WI \\ 3. University of North Dakota, Grand Forks, ND \\ 4. University of Akron, Akron, $\mathrm{OH}$ \\ * corresponding author: 2000 Columbia Hall, Grand Forks, ND 58202; phone: 707-777-6824; \\ fax: 701-777-3454; email: raeann.anderson@und.edu \\ Acknowledgments: Thank you to the research assistants who helped collect data for this study: \\ Julie Bremer, Briana Charlton, Lindsay Fero, Katrina Folberg, Kali McDonnell, Miranda \\ Miscikowski, Taylee Murray, Samantha Omellian, Caryssa Retrum, and Melanie Wamboldt. \\ Thank you to my dissertation committee for helping me craft this study: Shawn Cahill, Colleen \\ Heinkel, Christine Larson, Diane Reddy, and Robyn Ridley. Thank you to the participants who \\ shared their stories with us. Finally, thank you to the contributors of my kickstarter campaign \\ who helped fund my labor on this project
}




\begin{abstract}
The current study examined how psychological factors influence hypothetical behavioral responses to threat (BRTT). College women $(n=113)$ with a history of sexual victimization completed a standardized lab-based self-defense scenario. Interpersonal skills, coping style, and assertive and non-assertive BRTT during a prior assault predicted assertive BRTT during the task. The use of non-assertive BRTT during past assaults no longer predicted assertive BRTT during the task when accounting for rape acknowledgment. Findings regarding rape acknowledgment demonstrate the complexity of recovery from sexual assault. Our results highlight interpersonal skills as an intervention target for innovative sexual assault risk reduction interventions.
\end{abstract}

Keywords:

Rape, assessment, revictimization, childhood sexual abuse, self-defense 
Predictors of Assertive and Non-Assertive Styles of Self-Defense Behavior during a Lab-based Sexual Assault Scenario

Rape affects approximately $25 \%$ of college women and is associated with a wide range of negative physical and mental health consequences including increased rates of posttraumatic stress disorder (PTSD: Carey, Durney, Shepardson, \& Carey, 2015; Martin, Macy, \& Young, 2011). An even larger proportion of women endure sexual assault experiences without meeting the legal definition of rape (Koss, 1998). Yet, the science and efficacy of interventions for sexual assault risk reduction are limited in comparison to interventions for other common conditions such as depression or PTSD (Untied \& Orchowski, 2013). Many of the most promising sexual assault risk reduction interventions (for example see, Gilmore, Lewis, \& George, 2015; Senn et al., 2015) incorporate Feminist Self Defense (for a review see: Gidycz \& Dardis, 2014). Feminist self defense increases assertive behavioral responses to threat (BRTT) and includes ways to overcome barriers to assertive BRTT (Senn et al., 2015; Simpson Rowe, Jouriles, \& McDonald, 2012, 2015). Yet, assertive BRTT is not the only response to the threat of sexual assault. The efficacy of feminist self defense may be enhanced by a greater understanding of what psychological factors are associated with different types of BRTT in order to facilitate effective responses and decrease ineffective responses. However, care should be taken to not insinuate victim-blaming when investigating response styles to coercion. The responsibility for rape rests solely with the perpetrator.

The present study aimed to identify factors associated with a woman’s likelihood of endorsing three common styles of BRTT (assertive, diplomatic, and immobile) during a laboratory scenario. In this manuscript, we define BRTT as any behaviors that are elicited by the threat of sexual assault, including both voluntary and involuntary behaviors (Anderson \& Cahill, 
2015). At least two styles of non-assertive BRTT have been consistently characterized by past research: diplomatic style responses (those that attempt to accommodate social and interpersonal concerns) and immobile style responses (those characterized by involuntary “freezing” or a lack of ability to respond forcefully and directly, Nurius, Norris, Young, Graham, \& Gaylord, 2000); yet these styles are poorly understood. We specifically focused on a population at high-risk for sexual assault: women with a history of repeated sexual victimization. We also sought to explore whether there was a relationship between past BRTT during prior victimization experiences (i.e., the behavioral responses in the participant's real life) and lab BRTT (i.e., the behavioral responses to a lab-based scenario displayed in the current study). Our investigation was grounded in the integration of ecological framework theory developed by Messman-Moore and Long (2003) with the cognitive ecological model of women’s responses to male sexual coercion proposed by Nurius \& Norris (1995).

\section{$\underline{\text { BRTT and Prior Sexual Victimization }}$}

Retrospective studies have consistently found a link between sexual victimization history and the use of non-assertive behavioral responses to threat (reviewed in Anderson \& Cahill, 2015; Tirabassi, Caraway, \& Simons, 2016). Recent research indicates that the links between BRTT and victimization are most pronounced for those who have experienced developmental revictimization, or sexual victimization in two different developmental periods (Anderson, Cahill, \& Delahanty, 2018). However, these nuances regarding the impact of prior sexual victimization on BRTT are only recently being examined.

Many sexual violence survivors do not label (i.e., acknowledge) their experiences as rape, but instead, use benign and minimizing labels such as "bad sex.” A recent meta-analysis examined the prevalence of unacknowledged rape and found that the overall weighted mean 
percentage of unacknowledged rape was $60.4 \%$ (Wilson \& Miller, 2016). It is theorized that the inability to acknowledge that one has been a victim of a crime could increase one's vulnerability to future victimization, perhaps by the inability to recognize the threat. Acknowledgment of victimization (i.e., "rape acknowledgment”) is an important characteristic of victimization that is tied to adaptive coping and decreased risk for revictimization (Littleton, Axsom, Breitkopf, \& Berenson, 2006). Despite its clinical importance, acknowledgment status has not been examined in relation to BRTT.

\section{Relationship between BRTT during Prior Victimization and Lab-based BRTT}

The relationship between past and present behavioral responses to threat is unclear. Although research has found significant relationships between the type of BRTT used in a hypothetical scenario and the type used in response to actual threats experienced during a followup period (Gidycz, Van Wynsberghe, \& Edwards, 2008; Turchik, Probst, Chau, Nigoff, \& Gidycz, 2007), research has not examined how past BRTT relates to intended BRTT during a lab-based task. Behavioral theory suggests a correspondence between past BRTT and future BRTT which may be especially pronounced for some types of BRTT, such as immobile (Marx, Heidt, \& Gold, 2005). Immobile BRTT include tonic immobility (TI), a component of the physiological fight-flight-freeze response that occurs in the presence of a threat. TI is a sustained and involuntary physical immobility that can be elicited by trauma stimuli; it is a trauma-related, conditioned response (Zoellner, 2008). Women with a history of childhood sexual abuse (CSA) are highly likely to report TI; in one study, over $52 \%$ of participants reported TI in response to CSA (Heidt, Marx, \& Forsyth, 2005). TI may be a conditioned response for some CSA survivors; thus, participants with a history of sexual victimization (especially those victimized in childhood) may be more likely to also report immobile BRTT and other non-assertive BRTT in 
lab-based tasks. Immobile BRTT are important to understand as they have been associated with increased risk for sexual assault (Macy, Nurius, \& Norris, 2007; Turchik et al., 2007). Sexual assault risk reduction interventions may be improved by not only increasing assertive BRTT and facilitating factors for assertive BRTT but by simultaneously decreasing less effective responses, such as immobile BRTT, and targeting risk factors for these behaviors.

\section{Theoretical Background \& BRTT}

Ecological framework theory underscores the important role of psychological factors, including specific types of psychopathology, in understanding repeated victimization (MessmanMoore \& Long, 2003). This theory posits that specific psychological vulnerabilities, such as history of abuse, psychiatric symptoms, coping style, and interpersonal schemas may increase vulnerability to victimization by interfering with a person's ability to recognize or respond to risk (Messman-Moore \& Long, 2003). Prior sexual abuse and emotion dysregulation have been repeatedly tied to risk of sexual victimization (Messman-Moorre, Walsh \& DiLillo, 2010; Messman-Moore, Ward \& Zerubaval, 2013); yet other trait-like vulnerabilities, such as interpersonal skills and coping, have been less investigated. Given the availability of psychological interventions to improve interpersonal skills and coping skills (e.g., dialecticalbehavior therapy) and findings demonstrating how interpersonal skills are adversely affected by CSA (DiLillo, 2001), knowing how these constructs relate to behavioral responses to threat is important for understanding BRTT and designing effective sexual assault risk reduction interventions for those with a history of CSA.

Consistent with ecological framework theory, the cognitive ecological model (Nurius \& Norris, 1995) focuses on how immediate psychological antecedents, including situational characteristics (e.g., relationship to the perpetrator), are influenced by existing emotional and 
cognitive processes to influence BRTT. For example, feeling self-conscious predicts diplomatic BRTT (Nurius et al., 2000). This body of work has demonstrated how the characteristics of the threatening situation interact with existing background factors; for example, women with a history of sexual victimization tend to display less anger in lab BRTT tasks (Jouriles, Simpson Rowe, \& McDonald, 2014). Other research has tied interpersonal factors, such as relationship expectancies, to BRTT (Macy, Nurius, \& Norris, 2006; Turchik et al., 2007). In the cognitiveecological model, prior sexual victimization changes the emotional and cognitive processes that facilitate accurate appraisals of risk and therefore, response. Yet, little research has synthesized these two theories which tend to focus, respectively, on trait-like psychological vulnerabilities (e.g. emotion regulation, interpersonal skills) and state-like responses to the threat (e.g., barriers to responses, emotional reactions) in a single model to examine BRTT. In spite of the theoretical importance of BRTT, the inclusion of BRTT in intervention approaches, and the link between BRTT and victimization, little is known regarding psychological factors that may facilitate different types of BRTT. Further exploration of this gap is important, given the number of psychological interventions with demonstrated efficacy at improving targets such as emotion regulation, coping, and interpersonal skills (e.g., cognitive-behavioral therapies).

\section{Current Study}

Prior work has highlighted factors associated with behavioral responses to threat in women with sexual victimization histories, but the heterogeneity and varied severity of each participant's assaults confounds the assessment of threat severity, BRTT, and any covarying psychological factors (Gidycz et al., 2008; Nurius et al., 2000; Turchik et al., 2007). The current study sought to address some of the methodological limitations inherent in previous research while synthesizing ecological framework theory and the cognitive-ecological model. Our goal 
was to investigate predictors of BRTT styles in a high-risk group (college women with a history of sexual victimization) using a low-cost laboratory paradigm of a self-defense task to standardize the threat stimulus used to elicit BRTT. Stimulus standardization allows us to disentangle the effects of individual differences from situational factors. We also sought to explore how BRTT during a prior victimization experience corresponded to BRTT during the lab-based task. Specifically, goals of the study included:

1. Identify predictors of each BRTT style (assertive, diplomatic, immobile). We hypothesized that both psychological trait-like domains (e.g., interpersonal skills, emotion regulation, coping style) and state-like factors (e.g., perceived barriers to responding to aggression, emotional states) would be predictive of BRTT style endorsed during the task.

2. Explore the relationship between past BRTT and lab BRTT including victimization history variables such as rape acknowledgment. We hypothesized that there would be a smallmoderate positive correlation between each style of past BRTT and the same style of lab BRTT (e.g., assertive would predict assertive).

\section{METHOD}

\section{$\underline{\text { Participants }}$}

Participants were 113 college women with a history of lifetime sexual victimization. Participants were recruited from the University of the second author; a large, urban, Great Lakes region, public institution with a size-able proportion of first-generation, diverse, and commuter students. The mean age of participants was 23.1 years $(S D=6.2)$. Most participants identified as Caucasian (78.8\%) and heterosexual (89.2\%); 14.2\% identified as African-American, 7.1\% as Asian/Asian-American, $4.4 \%$ as Native American, and $4.4 \%$ as Latina. The modal family income was $\$ 60,000-\$ 79,999$. The average number of years in college was $2.7(S D=2.1)$, and 
psychology majors accounted for $48.6 \%$ of the sample. Almost one-half the sample endorsed childhood sexual abuse (45.1\%), most endorsed adolescent/adult sexual assault (81.4\%), and approximately one-third endorsed developmental revictimization (sexual victimization in two developmental periods, 31.9\%). Portions of this study have been presented in prior research examining the sequence of behavioral responses to threat behaviors that participants engaged in during the lab task (Anderson et al.,, 2018).

Procedures

The following procedures were approved by the Institutional Review Board of the second author's university. Potential participants $(\mathrm{N}=508)$ were screened for eligibility via an online questionnaire using the 5 items from the Childhood Sexual Abuse subscale of the Childhood Trauma Questionnaire-Short Form (Bernstein et al., 1994) and items assessing completed sexual coercion and rape (items 8-13) from the Sexual Experiences Survey (Koss \& Oros, 1982). During private appointments, participants self-administered all study questionnaires and completed the behavioral responses to threat task. The questionnaire battery and the BRTT task administration were counterbalanced; 52 participants completed questionnaires first, while 61 participants completed the BRTT task first. After completing the study, all participants were debriefed by a female undergraduate research assistant. The debriefing procedure included providing participants with an information packet (also read aloud) that contained fact sheets explaining the goals of the study, a statement debunking rape myths that may have been activated by the study topic, and a list of available clinical resources for sexual violence survivors. During the final step of the debriefing procedure, participants were invited to ask questions about the study, and provide information on what if any parts of the study they found upsetting. A female graduate student (the first author) was available on hand for participants who 
either a) indicated a desire or b) were identified by undergraduate research assistants as in need of, more in-depth conversation or screening for clinical services. Two participants completed screening for clinical services and were provided a referral.

Behavioral responses to threat task. BRTT were elicited and measured using the previously validated, adapted version of the response latency paradigm as a lab-based assessment of self-defense behavior (Anderson \& Cahill, 2014; Marx \& Gross, 1995). Prior research has found good evidence of validity for this scenario; prior responses have been associated with sexual victimization and psychophysiological responses (Soler-Baillo, Marx, \& Sloan, 2005). In this task, participants listened to an audio recording of a stereotypical, heterosexual, date rape scenario: a couple talking in a man’s apartment after a date at the movies. Specifically, at 138 seconds, the man has violated the woman's boundaries twice with the woman explicitly communicating her desires and limits each time. The recording ends with the woman saying angrily, “Haven’t you been listening? I just told you not to touch my chest and now you touch my butt.” Before listening, they were instructed to imagine themselves in the scenario, and at a point unknown to the participant, the recording automatically paused wherein they were instructed to record their hypothetical response to the scenario, "how would you react in response to the situation you just listened to?” by rating each Behavioral Response Questionnaire (BRQ) item. Prior research indicates that the scenario represents a moderate to severe level of threat (Pumphrey-Gordon \& Gross, 2007; Soler-Baillo et al., 2005) and has been rated as realistic (Marx \& Gross, 1995).

$\underline{\text { Measures }}$ 
All study measures were validated by prior research; internal consistency for each measure in this study is reported using Cronbach's alpha except when noted otherwise. All study measures were scored following the instructions of the original authors or most current literature.

Task questionnaires. The following questionnaires were administered as part of the labbased self-defense task and are described in order of administration. The Positive and Negative Affect Schedule (PANAS) and the Barriers to Sexual Aggression Scale (BRSA) were included in order to assess current mood and psychological barriers as potential predictors of task behavioral responses to threat (Nurius et al., 2000; Jouriles, Simpson Rowe, \& McDonald, 2014).

The PANAS (Watson, Clark, \& Tellegen, 1988) was used to assess mood before and after completing the task. We administered the PANAS prior to the task in order to control for pre-task mood on BRTT. Participants rated each of 20 emotions such as "anger" on a Likert scale from 1 "slightly or not at all” to 5 "extreme” regarding their current emotional state. The PANAS consists of three subscales: positive affect $(\mathrm{PA}$, alpha $\mathrm{pre}=.91)$, negative affect $(\mathrm{NA}$, alpha $\left._{\text {pre }}=.84\right)$, and affective polarity (AP, alpha ${ }_{\text {pre }}=.66$, Leue \& Beauducel, 2011).

The Behavioral Response Questionnaire (BRQ; Nurius et al., 2000) was used to assess three hypothetical BRTT styles during the lab self-defense task. The BRQ is the most frequently used measure of BRTT and is the only currently available measure that captures multiple types of BRTT. Participants rated each of the 27 items on a five-point Likert scale from 0 "not at all like my response” to 4 “very much like my response.” We slightly modified the items to use present tense. BRQ responses can be reduced to three subscales; assertive (BRQ-A, alpha = .83), diplomatic (BRQ-D, alpha = .69), and immobile (BRQ-I, alpha = .59). Although the immobile scale reliability was low, it is similar to other published research (alpha $=.54$, Macy, Nurius, \& Norris, 2007). Items from the assertive subscale include "tell him clearly and directly that I want 
him to stop,” “push him away,” and "become physically defensive (e.g., hit, kick, scratch)”. In contrast to assertive items, diplomatic scale items indirectly or gently respond to the threat. Immobile items are defined by a lack of response related to emotional distress. Examples from the diplomatic and immobile scales, respectively, include: "jokingly tell him he is coming on too strong” and “...I feel almost paralyzed and unresponsive”. Total scores for each BRQ subscale were used in this study.

The Barriers to Sexual Aggression Scale (BRSA: Nurius et al., 2000) was administered to assess state psychological barriers to engaging in active behavioral responses. The BRSA contains 22 items that address a range of potential barriers to engaging in an active BRTT. We slightly modified items to use the present tense. The BRSA can be scored multiple ways; we used factor analysis to empirically derive three subscales, similar to those used in past research: fear of injury (two items, alpha $=.65$ ), alcohol as impeding actions (three items, alpha $=.91$ ), and self-judgment/relationship concerns (alpha $=.94)$. Each item, such as "I am too embarrassed to get up and run out of the room” (BRSA - self-judgment/relationship concerns) is rated on a fivepoint scale from 0 "not at all” to 4 "very difficult."

The BRQ and the BRSA were developed empirically using descriptions from sexual assault survivors (Nurius et al., 2000). Both were administered twice, once during the task and once during the questionnaire battery. The second administration assessed responses to past assaults. For the BRQ-past and BRSA-past participants were instructed to complete these questionnaires regarding the "worst” assault experienced, consistent with prior research (Macy et al., 2007).

The Responses to Script-Driven Imagery Scale (RSDIS; Hopper, Frewen, Sack, Lanius, \& van der Kolk, 2007) was used to assess dissociative reactions during the threat-response task 
given the high rate of PTSD/dissociation in sexual trauma survivors (Heidt et al., 2005). Instructions were slightly adapted to assess reactions to the task rather than script-driven imagery. Participants rated four items such as “did you feel like you were in a fog?” on a sevenpoint Likert scale from 0 "not at all” to 6 "a great deal.” The RSDIS had adequate internal consistency in this study, alpha $=.65$.

Questionnaire battery. The remaining questionnaires were administered in a randomized order with the victimization history questionnaires administered as a block.

The 36-item Difficulties in Emotional Regulation Scale (DERS; Gratz \& Roemer, 2004) assessed emotion dysregulation, a common sequela of sexual victimization. Participants rated items, such as "I experience my emotions as overwhelming and out of control" on a 5-point Likert scale from 1 "almost never, 0 -10\%” to 5 “almost always, 91-100\%”. The DERS can be reduced to six subscales: acceptance of emotions (alpha $=.91$ ), engaging in goals while emotional (alpha $=.66)$, impulse control $($ alpha $=.74)$, emotional awareness $($ alpha $=.87)$, emotion regulation strategies (alpha $=.88)$, and emotional clarity (alpha $=.50)$.

The Inventory of Interpersonal Skills-32 (IIP-32: Barkham, Hardy, \& Startup, 1996) was used to assess interpersonal skills, as interpersonal difficulties are a frequent concern for sexual victimization survivors (DiLillo, 2001). Participants rated 32 items that were divided into two different response formats: "things you find hard to do with other people" and "things that you do too much." Example items are, "disagree with other people” and "I open up to people too much," respectively. Each item is rated on a 5-point Likert scale from 0, "not at all” to 4, "extremely." The IIP-32 can be reduced to 8 subscales: hard to be assertive (alpha $=.85$ ), too caring (alpha $=.76)$, too dependent (alpha $=.64)$, hard to be sociable (alpha $=.84)$, hard to be 
supportive (alpha $=.83)$, too aggressive $($ alpha $=.85)$, and hard to be involved (alpha $=.81)$. The openness subscale was not used in this study due to poor internal consistency (alpha $<.3$ ).

The Brief COPE (COPE; Carver, 1997) is a widely used measure of coping style. Participants' rated 28 items on a 4-point Likert scale from 0, “I haven’t been doing this at all” to 3, "I’ve been doing this a lot" regarding how they cope with stress in their life. The COPE reduces to 14 subscales, each containing two items. An example item is "I've been using alcohol or other drugs to get help me get through it.” Selected subscales were used in this study based on past research: acceptance $($ alpha $=.73)$, emotional support $($ alpha $=.83)$, disengagement $($ alpha $=$ $.75)$, substance use (alpha $=.97)$, and the active coping scale (10 items, alpha $=.89$ ).

Victimization history questionnaires. Victimization history questionnaires are listed below in the order of administration.

The Childhood Trauma Questionnaire - Childhood Sexual Abuse subscale is a wellvalidated measure (CTQ-CSA: Bernstein et al., 1994) that was administered to assess the history of CSA. The CTQ-CSA contains five items such as "someone threatened to hurt me or tell lies about me unless I did something sexual with them” before age 14 and are rated on a scale from 0 “never true” to 5 "very often true”.

The Revised Conflicts Tactics Scales - Sexual Coercion subscale (CTS2-SC: Straus, Hamby, Boney-McCoy, \& Sugarman, 1996) was used to assess sexual victimization within intimate partnerships. The CTS2-SC was included, as prior research has demonstrated that sexual victimization within romantic partnerships is common and frequently underestimated by measures of general sexual victimization (Moreau, Boucher, Hébert, \& Lemelin, 2014). The CTS2-SC uses paired items assessing the respondent's and their partner's behavior, for example: "I used force (like hitting, holding down, or using a weapon) to make my partner have oral or 
anal sex/My partner did this to me" and provides a frequency rating for each behavior in the past year $(0,2,3-5,6-10,11-20,20+$, not in the past year but it did happen before). In our sample, twelve participants who were identified as non-victims by the SES-SFV endorsed CTS2-SC victimization items.

The Sexual Experiences Survey-Short Form Victimization (SES-SFV: Koss et al., 2007) was used to assess adolescent/adult sexual victimization since age 14. The SES-SFV contains seven stem items which describe a sexual behavior followed by five possible coercive tactics for a total of 35 items assessing sexual victimization. An example item is, "someone had oral sex with me or made me have oral sex with them without my consent by taking advantage of me when I was too drunk or out of it to stop what was happening." More than half the sample reported experiencing rape on the SES-SFV $(n=65)$. Victimization acknowledgment was calculated by comparing SES-SFV and CTS2 scores for rape with responses to the SES-SFV acknowledgment item, “Have you ever been raped?” Prior research has found good evidence of validity (Davis et al., 2014) and adequate evidence of test-retest reliability in women (Johnson, Murphy, \& Gidycz, 2017). We did not calculate Cronbach’s alpha for the victimization history measures, consistent with recommendations that internal consistency is recommended for measures of latent constructs but inappropriate for measures of behavioral experiences (Diamantopoulos, Riefler, \& Roth, 2008; Koss et al., 2007). In the case of sexual victimization, there is no latent construct that in and of itself induces sexual victimization, given that sexual victimization is an experience ultimately caused by another person's behavior (Koss et al., 2007).

\section{RESULTS}

\section{Preliminary Analyses}


Initial analyses were conducted to examine whether Behavioral Response Questionnaire (BRQ) scores varied based on demographic factors or experimental procedures. Counterbalance condition was related to dissociation scores and Barriers to Sexual Aggression Scale (BRSA) task fear scores, such that participants in the task first condition reported higher scores. Race was related to past behavioral responses to threat scores such that African American women reported higher use of past assertive $[t(17.58)=2.41, p=.03]$ and diplomatic BRTT $[t(109)=2.61, p=$ .01]. Thus, we controlled for counterbalance condition and race in subsequent analyses.

Consistent with prior research finding that developmental revictimization has the most impact on BRTT (Anderson et al., 2018) and because our entire sample had a sexual victimization history, we controlled for developmental revictimization in the model rather than controlling for multiple victimization variables.

Aim 1 - Predictors of BRTT Styles.

To examine predictors of each behavioral responses to threat style during the lab-based scenario, hierarchical multiple regression models were computed predicting each style with variables accounted for in steps, following ecological framework theory and the cognitive ecological model. The first step was composed of historical variables: condition, race, sexual victimization, past BRQ, and BRSA scores. The second step consisted of variables that represent traits: interpersonal skills, emotion regulation, and coping. The third step represented states: emotions during the task and task BRSA scores. Results are summarized in Table 1. Past assertive BRTT, past diplomatic BRTT, past immobile BRTT, interpersonal assertion, interpersonal aggression, interpersonal involvement, and substance use coping were identified as 
Table 1 about here

significant predictors of assertive BRTT during the lab-based scenario, $F(11,98)=4.96, p<$ .001 , with a large effect size $\left(f^{2}=.56\right)$, Power $=.99$, accounting for $38 \%$ of the variance. For diplomatic BRTT during the scenario, only past immobile BRTT was identified as a predictor, $F(8,102)=6.48, p<.001$, with a large effect size $\left(f^{2}=.51\right)$, Power $=.99$. None of the examined variables were significant predictors of immobile BRTT during the scenario.

$\underline{\text { Aim } 2 \text { - Correspondence between Past and Lab BRTT. }}$

Pearson product correlations were computed to examine the relationship between past and lab BRTT scores. Past and lab BRTT scores of the same style were all significantly correlated in the moderate to strong range, $r=.3-.5$ (see Table 2). Past assertive responses were not related to diplomatic or immobile responses to the scenario. Similarly, past diplomatic or immobile responses were not related to assertive responses to the scenario.

Table 2 about here

These findings appear somewhat contradictory, that past non-assertive BRTT were not correlated with lab assertive BRTT but were significant predictors of lab assertive BRTT in the regression analyses. Given this, we next examined in post-hoc analyses how perceptions of past victimization experiences may explain the relationship between past BRTT and lab BRTT. Specifically, we examined whether acknowledged victimization served as a potential explanatory variable for the relationship between past and lab BRTT. Two separate hierarchical regression 
analyses were conducted predicting lab assertive and lab diplomatic BRTT, respectively. Similar to our strategy in Aim 1, we entered variables in steps to represent theoretical relationships. The first step included historical factors: past developmental victimization, acknowledgment status, and past barriers to BRTT. The second step included past BRTT scores.

In these analyses, only acknowledged victimization and past assertion were significant predictors of task assertion scores. Past diplomatic and immobile scores were no longer related to lab assertion. This model was significant, $F(9,100)=2.67, p<.01$, with a medium effect size $\left(f^{2}=.24\right)$, Power $=.96$, accounting for $19 \%$ of the variance (see Table 3 ). Similar analyses were conducted predicting lab diplomatic BRTT; there was no relationship between past diplomatic scores and lab diplomatic scores when including acknowledgment in the analyses. We did not conduct these analyses for immobile BRTT given that there was no significant relationship between past BRTT and lab immobile BRTT in the regression analyses above.

Table 3 about here

\section{DISCUSSION}

Sexual victimization is common on college campuses, yet interventions to reduce sexual victimization are limited (Carey et al., 2015; Untied \& Orchowski, 2013). The present study is one of the first to examine predictors of multiple styles of behavioral responses to threat (assertive, diplomatic, and immobile) in women with a history of sexual victimization using a standardized threat stimulus integrating ecological framework theory and the cognitiveecological model. This study is also one of the first to examine how past BRTT may be related to lab based BRTT. 
All three styles of past BRTT, interpersonal skills, and lack of substance use coping were predictive of assertive BRTT scores, highlighting psychological factors that facilitate the goal of feminist self-defense programs. To our knowledge, this is the first study to demonstrate the relationship between interpersonal skills and assertive BRTT. This is a critical finding: as emphasized by Nurius and Norris (1995), most sexual assaults take place in an ambiguous interpersonal context, and many of the barriers to responding to aggression are of a social and/or interpersonal nature. Interpersonal skills and a healthy skepticism may be an important precursor to assertive BRTT, yet interpersonal skills are rarely explicitly targeted in current interventions. We strongly link this finding to our methodology - the use of a standardized threat stimulus with limited interpersonal context highlights how important this construct is in understanding assertive BRTT. This is one of the first studies to highlight the role of interpersonal skills in BRTT and points to a new and innovative approach to sexual assault risk reduction interventions: interpersonal skills as a potential intervention target.

Contrary to hypotheses, emotion regulation was not a predictor of BRTT. This was surprising, given the research on emotion regulation and sexual revictimization (MessmanMoore, Walsh, \& DiLillo, 2010; Messman-Moore, Ward, \& Zerubavel, 2013). It is possible that this effect was subsumed by the interpersonal skills variable, given the theoretical relationship between these two constructs (Linehan, 1993) and their high intercorrelation in this study $(r=$ .66). We recommend future research on this topic. Consistent with prior research linking substance use coping to the risk of revictimization, substance use coping was a negative predictor of assertive BRTT (Messman-Moore, Ward, \& Brown, 2008; Messman-Moore et al., 2013). This finding underscores the validity of this paradigm (given that substance use was not 
primed in the vignette stimuli) for assessing risk factors related to BRTT and the importance of sexual assault risk reduction interventions to target substance use.

We did not identify any state-like predictors (including emotional reactions) of BRTT; it is possible that our state measures (Barriers to Sexual Aggression Scale, The Positive and Negative Affect Schedule) may not have been well-suited to measure state changes associated with a lab-based task. It is also possible that the states which would predispose a person to these styles are more intense and would not be elicited by our task; these states might also be very different than the emotions and psychological barriers we chose to assess. For example, the potentially necessary conditions affecting the susceptibility to and duration of tonic immobility (TI) are extreme fear, physical contact, and the perception of inescapability; thus, the events leading to TI are by definition extreme (Zoellner, 2008). It is possible that this hypothetical scenario (and others) may not be able to elicit TI. We recommend future research continue to examine state predictors and how state-like and trait-like factors may interact to moderate or mediate responses to the task.

We were not able to identify significant predictors for immobile BRTT. This result may have multiple explanations. The lack of significant predictors may be due to methodological flaws pertaining to the failure of the Behavioral Response Questionnaire (BRQ) to adequately capture the construct of both TI specifically, and immobile style responses, holistically. Immobile BRTT are also less common as the dominant response behavior (Anderson et al., 2018). Despite these limitations, the BRQ is the most frequently used measure of BRTT, and it is the only measure that captures multiple response types. Our results highlight the importance of further investigations into immobile response styles and the construct of TI, including the development of methodologically sound research instruments. 
To our knowledge, this is the first study to examine how past BRTT relate to current (labbased) BRTT. Consistent with our hypotheses and behavioral theory, past BRTT were moderately related to lab-based BRTT. In addition, all three styles of past BRTT were related to assertive BRTT in the lab. Yet after controlling for rape acknowledgment, only past assertive BRTT continued to be predictive of lab assertive BRTT. Past immobile behavior was predictive of lab diplomatic BRTT, but not after controlling for acknowledgment. We interpret these results through a cognitive-behavioral and social learning paradigm. As women receive cultural messages that they are responsible for rape, they learn through trial and error what behaviors may be most protective. In essence, the results of different past BRTT predicting lab-based assertive BRTT may be indicative of a “learning curve” whereby vulnerable young women’s ability to assert themselves in high-risk scenarios increases through active coping and skill building after experiences of victimization. Thus, acknowledgment may be a sign of active coping. Past research has identified rape acknowledgment as an important clinical marker related to multiple positive clinical processes. Yet this was the first study to connect rape acknowledgment with BRTT (Littleton, Axsom, \& Grills-Taquechel, 2009; Littleton et al., 2006). Perhaps women who can accurately label their past experiences as coercive and violating are able to eventually take active steps in reducing their risk, assuming they have support in their recovery. Thus, those who were able to acknowledge their victimization experience as rape may have been able to reflect on past experiences to form their response to the lab task.

\section{Clinical Implications}

Results of the current study have important implications relating to sexual assault risk reduction programming and therapeutic interventions for sexual assault survivors at high-risk of repeated victimization. First, the present lab-based paradigm can be useful for sexual assault risk 
reduction interventions to assess whether the intervention is indeed changing the target behaviors by assessing behavioral responses to threat utilized both pre- and post-intervention. This paradigm can also be used to create risk classifications to match participants to varying levels of intervention.

The current study's results can also inform feminist, culturally competent therapy. For individuals with histories of sexual trauma who want to reduce their risk of future victimization, a therapist can utilize aspects of the Behavioral Response Questionnaire (BRQ) and facilitate a dialogue regarding a patient's risks and response styles, identifying both strengths and barriers to effective responding. Our results also highlight the crucial role of interpersonal skills in assertive responding, underscoring the necessity of exploring interpersonal skills as an explicit intervention target for sexual assault risk reduction interventions. Clinicians should also integrate both assertiveness training and interpersonal skills training modules into their therapeutic work with individuals recovering from sexual trauma, drawing on empiricallysupported treatments such as DBT and empowerment feminist therapy (e.g., Linehan, 1993; Worell \& Remer, 1992).

Therapists should also be mindful of how a patient's identities affect their propensity toward different response options, as assertiveness and communication patterns can vary by gender, culture, and other demographic variables (e.g., Costa, Terracciano, \& McCrae, 2001; Mortenson, 2009). Survivors of sexual trauma are never responsible for their victimization, and an understanding of the contextual factors that allow sexual violence to continue can alleviate self-blame.

\section{Limitations}


This sample was relatively small and homogeneous, though adequately powered for these analyses. Future research with larger and more diverse samples is strongly recommended. Particularly, we recommend research designs that are culturally sensitive, as the strategies that women may perceive as helpful or those that they feel capable of enacting are based in social relationships that are cemented in culture (Nguyen et al., 2016). For example, the stimuli used in this study portrayed a heterosexual, stereotypical middle-class date, which may not be relatable to sexual minority participants or those from non-middle-class backgrounds. However, the utility and simplicity of the standardized threat stimulus utilized in the current study would be easy to customize for diverse groups, and it has been customized in the past (Winslett \& Gross, 2008). Additionally, although this study used the most comprehensive assessment of behavioral responses to threat available, qualitative research indicates that the range of BRTT is quite broad and likely not fully captured by the Behavioral Response Questionnaire (BRQ: Anderson, Brouwer, Wendorf, \& Cahill, 2016; Masters, Norris, Stoner, \& George, 2006), especially the construct of tonic immobility. Further, women also tend to engage in multiple response patterns in the same scenario; more research is needed to understand the sequence of behavior in BRTT and how they may be related to clinical constructs (Anderson et al., 2018).

Notably, assertiveness is viewed differently based on women's intersectional identities and cultural backgrounds. Assertiveness can be penalized in some contexts, such as for African American women (e.g., boldness in black females is denigrated through stereotypes of the "angry Black woman”) (Walley-Jean, 2009). A cultural difference in utilizations of assertiveness was observed in the current study, as African American women endorsed more assertive BRTT in past assaults in comparison to other ethnic/racial groups. The extant theoretical models of women's responses to male sexual coercion do not capture the ways in which factors such as 
age, race/ethnicity, socioeconomic status, and cultural background impact experiences and outcomes, nor do they address the complex interplay of victim identity with perpetrator characteristics and assault-specific factors (Nurius and Norris; 1996). Future research should address these gaps.

$\underline{\text { Conclusions }}$

The present study systematically examined the extent to which past victimization and psychological factors impacted hypothetical behavioral responses to threat styles (assertive, diplomatic, and immobile) endorsed during a lab-based self-defense sexual assault scenario. Our study may be the first to integrate ecological framework theory and the cognitive-ecological model in investigating sexual victimization and BRTT. Results of this study identified interpersonal skills as predictors of assertive BRTT, highlighting interpersonal skills interventions as a future area for sexual assault risk reduction programs. Our results also demonstrate the utility of lab-based scenarios as research and clinical assessment tools. In sum, considering the prevalence of sexual assault, our results highlight ways to improve sexual assault risk reduction interventions as a key method to empower women to recognize and cope with high-risk situations. 


\section{References}

Anderson, R. E., Brouwer, A., Wendorf, A. R., \& Cahill, S. P. (2016). Women’s behavioral responses to the threat of a hypothetical date rape stimulus: A qualitative analysis. Archives of Sexual Behavior, 45, 793-805. doi.org/10.1007/s10508-015-0682-2

Anderson, R. E., \& Cahill, S. P. (2014). Use of the response-latency paradigm for eliciting and evaluating women's responses to the threat of date rape. Violence and Victims, 29, 248-261. doi.org/10.1891/0886-6708.VV-D-12-00101R1

Anderson, R. E., \& Cahill, S. P. (2015). Behavioral response to threat (BRTT) as a key behavior for sexual assault risk reduction intervention: A critical review. Aggression and Violent Behavior, 25, 304-313. doi.org/10.1016/j.avb.2015.09.015

Anderson, R. E., Cahill, S. P., \& Delahanty, D. L. (2018) Differences in the Type and Sequence Order of Self-Defense Behaviors during a High-Risk Victimization Scenario: Impact of Prior Sexual Victimization. Psychology of Violence Special Issue: Violence in Situ, 8(3) 339-348. doi: 10.1037/vio0000169

Barkham, M., Hardy, G. E., \& Startup, M. (1996). The IIP-32: A short version of the Inventory of Interpersonal Problems. British Journal of Clinical Psychology, 35, 21-35. doi.org/10.1111/j.2044-8260.1996.tb01159.x

Bernstein, D. P., Fink, L., Handelsman, L., Foote, J., Lovejoy, M., Wenzel, K., ... Ruggiero, J. (1994). Initial reliability and validity of a new retrospective measure of child abuse and neglect. The American Journal of Psychiatry, 151, 1132-6.

Carey, K. B., Durney, S. E., Shepardson, R. L., \& Carey, M. P. (2015). Incapacitated and forcible rape of college women: Prevalence across the first year. Journal of Adolescent Health, 56, 678-680. doi.org/10.1016/j.jadohealth.2015.02.018 
Carver, C. S. (1997). You want to measure coping but your protocol's too long: Consider the Brief COPE. International Journal of Behavioral Medicine, 4, 92-100. doi.org/10.1207/s15327558ijbm0401_6

Costa, P., Terracciano, A., \& McCrae, R. R. (2001). Gender differences in personality traits across cultures: Robust and surprising findings. Journal of Personality and Social Psychology, 81, 322-331

Davis, K. C., Gilmore, A. K., Stappenbeck, C. A., Balsan, M. J., George, W. H., \& Norris, J. (2014). How to score the Sexual Experiences Survey? A comparison of nine methods. Psychology of Violence, 4, 445-461. doi.org/10.1037/a0037494

Diamantopoulos, A., Riefler, P., \& Roth, K. P. (2008). Advancing formative measurement models. Journal of Business Research, 61, 1203-1218. doi.org/10.1016/j.jbusres.2008.01.009

DiLillo, D. (2001). Interpersonal functioning among women reporting a history of childhood sexual abuse: Empirical findings and methodological issues. Clinical Psychology Review, 21, 553-576. doi.org/10.1016/S0272-7358(99)00072-0

Gidycz, C. A., Van Wynsberghe, A., \& Edwards, K. M. (2008). Prediction of women’s utilization of resistance strategies in a sexual assault situation: A prospective study. Journal of Interpersonal Violence, 23, 571-588. doi.org/10.1177/0886260507313531

Gidycz, C., \& Dardis, C. (2014). Feminist self-defense and resistance training for college students: A critical review and recommendations for the future. Trauma, Violence, \& Abuse, 15, 322-333. doi.org/10.1177/1524838014521026 
Gilmore, A. K., Lewis, M. A., \& George, W. H. (2015). A randomized controlled trial targeting alcohol use and sexual assault risk among college women at high risk for victimization. Behaviour Research and Therapy, 74, 38-49. doi.org/10.1016/j.brat.2015.08.007

Gratz, K. L., \& Roemer, L. (2004). Multidimensional assessment of emotion regulation and dysregulation: Development, factor structure, and initial validation of the difficulties in emotion regulation scale. Journal of Psychopathology and Behavioral Assessment, 26, 4154. doi.org/10.1023/B:JOBA.0000007455.08539.94

Heidt, J. M., Marx, B. P., \& Forsyth, J. P. (2005). Tonic immobility and childhood sexual abuse: a preliminary report evaluating the sequela of rape-induced paralysis. Behaviour Research and Therapy, 43, 1157-71. doi.org/10.1016/j.brat.2004.08.005

Hopper, J. W., Frewen, P. A., Sack, M., Lanius, R. A., \& van der Kolk, B. A. (2007). The responses to Script-Driven Imagery Scale (RSDI): Assessment of state posttraumatic symptoms for psychobiological and treatment research. Journal of Psychopathology and Behavioral Assessment, 29, 249-268. doi.org/10.1007/s10862-007-9046-0

Johnson, S. M., Murphy, M. J., \& Gidycz, C. A. (2017). Reliability and validity of the Sexual Experiences Survey-Short Forms Victimization and Perpetration. Violence and Victims, 32, 78-92. doi.org/10.1891/0886-6708.VV-D-15-00110

Jouriles, E. N., Simpson Rowe, L., \& McDonald, R. (2014). Women’s expression of anger in response to unwanted sexual advances: Associations with sexual victimization. Psychology of Violence, 4, 170-183. doi.org/10.1037/a0033191

Koss, M. P. (1998). Hidden rape: Sexual aggression and victimization in a national sample of students in higher education. In Confronting rape and sexual assault (pp. 51-69). Wilmington, DE: SR Books/Scholarly Resources. 
Koss, M. P., Abbey, A., Campbell, R., Cook, S., Norris, J., Testa, M., ... White, J. (2007). Revising the SES: A Collaborative process to improve assessment of sexual aggression and victimization. Psychology of Women Quarterly, 31, 357-370. doi.org/10.1111/j.14716402.2007.00385.x

Koss, M. P., \& Oros, C. J. (1982). Sexual Experiences Survey: A research instrument investigating sexual aggression and victimization. Journal of Consulting and Clinical Psychology, 50, 455-457.

Linehan, M. M. (1993). Cognitive-behavioral treatment of borderline personality disorder. Cognitive-behavioral treatment of borderline personality disorder. doi.org/10.1017/CBO9781107415324.004

Littleton, H., Axsom, D., \& Grills-Taquechel, A. (2009). Sexual assault victims’ acknowledgment status and revictimization risk. Psychology of Women Quarterly, 33, 3442. doi.org/10.1111/j.1471-6402.2008.01472.x

Littleton, H. L., Axsom, D., Breitkopf, C. R., \& Berenson, A. (2006). Rape acknowledgment and postassault experiences: How acknowledgment status relates to disclosure, coping, worldview, and reactions received from others. Violence and Victims, 21, 761-778. doi.org/10.1891/vv-v21i6a006

Macy, R. J., Nurius, P. S., \& Norris, J. (2006). Responding in their best interests: Contextualizing women's coping with acquaintance sexual aggression. Violence Against Women, 12, 478-500. doi.org/10.1177/1077801206288104

Macy, R. J., Nurius, P. S., \& Norris, J. (2007). Latent profiles among sexual assault survivors: implications for defensive coping and resistance. Journal of Interpersonal Violence, 22, 543-565. doi.org/10.1177/0886260506298841 
Martin, S. L., Macy, R. J., \& Young, S. K. (2011). Health and economic consequences of sexual violence. In J. W. White, M. P. Koss, \& A. E. Kazdin (Eds.), Violence against women and children, Vol 1: Mapping the terrain (pp. 173-195). Washington, DC, US: American Psychological Association. doi.org/10.1037/12307-008

Marx, B. P., \& Gross, A. M. (1995). An analysis of two contextual variables. Behavior Modification, 19, 451-463. doi.org/10.1177/01454455950194003

Marx, B. P., Heidt, J. M., \& Gold, S. D. (2005). Perceived uncontrollability and unpredictability, self-Regulation, and sexual revictimization. Review of General Psychology, 9, 67-90.

Masters, N. T., Norris, J., Stoner, S. A., \& George, W. H. (2006). How does it end? Women project the outcome of a sexual assault scenario. Psychology of Women Quarterly, 30, 291302. doi.org/10.1111/j.1471-6402.2006.00297.x

Messman-Moore, T. L., \& Long, P. J. (2003). The role of childhood sexual abuse sequelae in the sexual revictimization of women: An empirical review and theoretical reformulation. Clinical Psychology Review, 23, 537-571. doi.org/10.1016/S0272-7358(02)00203-9

Messman-Moore, T. L., Walsh, K. L., \& DiLillo, D. (2010). Emotion dysregulation and risky sexual behavior in revictimization. Child Abuse \& Neglect, 34(12), 967-976.

Messman-Moore, T. L., Ward, R. M., \& Brown, A. L. (2008). Substance use and PTSD symptoms impact the likelihood of rape and revictimization in college women. Journal of Interpersonal Violence, 24, 499-521. doi.org/10.1177/0886260508317199

Messman-Moore, T. L., Ward, R. M., \& Zerubavel, N. (2013). The role of substance use and emotion dysregulation in predicting risk for incapacitated sexual revictimization in women: Results of a prospective investigation. Psychology of Addictive Behaviors, 27, 125-132. doi.org/10.1037/a0031073 
Moreau, C., Boucher, S., Hébert, M., \& Lemelin, J. (2014). Capturing sexual violence experiences among battered women using the Revised Sexual Experiences Survey and the Revised Conflict Tactics Scales. Archives of Sexual Behavior, 44, 223-231. doi.org/10.1007/s10508-014-0345-8

Mortenson, S. T. (2009). Interpersonal trust and social skill in seeking social support among Chinese and Americans. Communication Research, 36, 32-53.

Nguyen, H. V., Jackson, M. A., Schacht, R. L., Ung, C. M., George, W. H., \& Pantalone, D. W. (2016). Asian American college women's in-the-moment responses to a dating violence situation. Asian American Journal of Psychology, 7, 176-184. doi.org/10.1037/aap0000050

Nurius, P. S., \& Norris, J. (1995). A cognitive ecological model of women's response to male sexual coercion in dating. Journal of Psychology \& Human Sexuality, 8, 117-139. doi.org/10.1300/J056v08n01_09

Nurius, P. S., Norris, J., Young, D. S., Graham, T. L., \& Gaylord, J. (2000). Interpreting and defensively responding to threat: Examining appraisals and coping with acquaintance sexual aggression. Violence and Victims, 15, 187-208.

Pumphrey-Gordon, J., \& Gross, A. M. (2007). Alcohol consumption and females’ recognition in response to date rape risk: The role of sex-related alcohol expectancies. Journal of Family Violence, 22, 475-485. doi.org/doi.org/10.1007/s10896-007-9104-0</a>

Senn, C. Y., Eliasziw, M., Barata, P. C., Thurston, W. E., Newby-Clark, I. R., Radtke, H. L., \& Hobden, K. L. (2015). Efficacy of a sexual assault resistance program for university women. The New England Journal of Medicine, 372, 2326-35. doi.org/10.1056/NEJMsa1411131 
Simpson Rowe, L., Jouriles, E. N., \& McDonald, R. (2012). Enhancing women’s resistance to sexual coercion: A randomized controlled trial of the DATE program. Journal of American College Health, 60, 211-218. doi.org/10.1080/07448481.2011.587068

Simpson Rowe, L., Jouriles, E. N., \& McDonald, R. (2015). Reducing sexual victimization among adolescent girls: A randomized controlled pilot trial of My Voice, My Choice. Behavior Therapy, 46(3), 315-27. doi.org/10.1016/j.beth.2014.11.003

Soler-Baillo, J. M., Marx, B. P., \& Sloan, D. M. (2005). The psychophysiological correlates of risk recognition among victims and non-victims of sexual assault. Behaviour Research and Therapy, 43, 169-181. doi.org/10.1016/j.brat.2004.01.004

Straus, M. A., Hamby, S. L., Boney-McCoy, S., \& Sugarman, D. B. (1996). The Revised Conflict Tactics Scales (CTS2): Development and preliminary psychometric data. Journal of Family Issues, 17, 283-316. doi.org/10.1177/019251396017003001

Tirabassi, C. K., Caraway, S. J., \& Simons, R. M. (2016). Women’s behavioral responses to sexual aggression: The role of secondary cognitive appraisals and self-regulation. Violence against Women, 23(14), 1689-1709. doi.org/10.1177/1077801216665482

Turchik, J. A., Probst, D. R., Chau, M., Nigoff, A., \& Gidycz, C. A. (2007). Factors predicting the type of tactics used to resist sexual assault: A prospective study of college women. Journal of Consulting and Clinical Psychology, 75(4), 605-614. doi.org/10.1037/0022006X.75.4.605

Untied, A. S., \& Orchowski, L. M. (2013). Interventions to reduce college women’s risk for sexual assault. In K. V Bletzer \& K. V. (Ed) Bletzer (Eds.), Assaults: Interventions, preventive strategies and societal implications. (pp. 83-100). Untied, Amy S.: Nova Science Publishers. 
Walley-Jean, J. C. (2009). Debunking the myth of the “Angry Black Woman”. An exploration of anger in young African American women. Black Women, Gender + Families, 3(2), 68-86. doi.org/10.1353/bwg.0.0011

Watson, D., Clark, L. A., \& Tellegen, A. (1988). Development and validation of brief measures of positive and negative affect: The PANAS scales. Journal of Personality and Social Psychology, 54, 1063-1070.

Wilson, L. C., \& Miller, K. E. (2016). Meta-Analysis of the prevalence of unacknowledged rape. Trauma, Violence \& Abuse, 17, 149-59. doi.org/10.1177/1524838015576391

Winslett, A. H., \& Gross, A. M. (2008). Sexual boundaries: An examination of the importance of talking before touching. Violence against Women, 14, 542-62. doi.org/10.1177/1077801208315527

Worell, J., \& Remer, P. (1992). Feminist perspectives in therapy: An empowerment model for women. Wiley series in psychotherapy and counselling.

Zoellner, L. A. (2008). Translational challenges with tonic immobility. Clinical Psychology: Science and Practice, 15, 98-101. doi: 10.1111/j.1468-2850.2008.00114.x 


\section{Tables}

Table 1

Hierarchical Regression Analysis Summaries for Psychological Factors Predicting Lab-based Assertive, Diplomatic, and Immobile Responses to Threat

\begin{tabular}{|c|c|c|c|c|c|c|}
\hline $\begin{array}{l}\text { Assertive Responses } \\
\text { Step and Predictor Variable }\end{array}$ & $B$ & SE B & $\beta$ & $R^{2}$ & $\Delta R^{2}$ & $p$ \\
\hline Step 1: historical factors & & & & $.14^{*}$ & $.14^{*}$ & \\
\hline condition & .63 & 1.11 & .05 & & & .57 \\
\hline African American (yes/no) & 2.55 & 1.72 & .14 & & & .14 \\
\hline dev. revictimization (yes/no) & -.01 & .69 & -.00 & & & .99 \\
\hline past assertion & .17 & .06 & .26 & & & $.01 *$ \\
\hline past diplomatic & -.73 & .31 & -.68 & & & $.02 *$ \\
\hline past immobile & .61 & .27 & .62 & & & $.03^{*}$ \\
\hline Step 2: trait-like factors & & & & $.36 *$ & $.22 *$ & \\
\hline IIP - aggression & .50 & .15 & .28 & & & $.002 *$ \\
\hline IIP - assertion & -.31 & .15 & -.19 & & & $.04 *$ \\
\hline IIP - involved & -.48 & .17 & -.28 & & & $.01 *$ \\
\hline substance use coping & -.80 & .34 & -.20 & & & $.02 *$ \\
\hline Step 3: state-like factors & & & & $.36^{*}$ & .00 & \\
\hline BRSA-lab judgment & -.03 & .07 & -.04 & & & .64 \\
\hline \multicolumn{7}{|l|}{ Diplomatic Responses } \\
\hline Step and Predictor Variable & $B$ & SE B & $\beta$ & $R^{2}$ & $\Delta R^{2}$ & $P$ \\
\hline Step 1: historical factors & & & & $.28 *$ & $.28 *$ & \\
\hline condition & 1.27 & .83 & .13 & & & .13 \\
\hline African American (yes/no) & .82 & 1.28 & .06 & & & .52 \\
\hline dev. revictimization (yes/no) & -.13 & .53 & -.02 & & & .80 \\
\hline past diplomatic & -.05 & .23 & -.07 & & & .82 \\
\hline past immobile & .43 & .21 & .46 & & & $.04 *$ \\
\hline Step 2: trait factors & & & & $.34 *$ & $.06 *$ & \\
\hline IIP - sociable & -.12 & .14 & -.10 & & & .37 \\
\hline IIP - involved & -.16 & .15 & -.12 & & & .28 \\
\hline acceptance coping & .44 & .24 & .15 & & & .07 \\
\hline \multicolumn{7}{|l|}{ Immobile Responses } \\
\hline Step and Predictor Variable & $B$ & SE B & $\beta$ & $R^{2}$ & $\Delta R^{2}$ & $P$ \\
\hline Step 1: historical factors & & & & $.31 *$ & $.31 *$ & \\
\hline condition & 1.71 & 1.00 & .15 & & & .09 \\
\hline African American (yes/no) & -.06 & 1.46 & -.00 & & & .97 \\
\hline dev. revictimization (yes/no) & .54 & .61 & -.08 & & & .38 \\
\hline past diplomatic & .04 & .31 & .04 & & & .91 \\
\hline past immobile & .34 & .29 & .39 & & & .25 \\
\hline BRSA- past alcohol & .28 & .17 & .18 & & & .10 \\
\hline Step 2: trait factors & & & & $.32 *$ & .02 & \\
\hline task dissociation & .18 & .11 & .14 & & & .10 \\
\hline
\end{tabular}


Table 2

Correlations between Past and Lab Behavioral Responses to Threat Scores, $N=111$ past- A past-D past-I lab-A lab-D lab-I

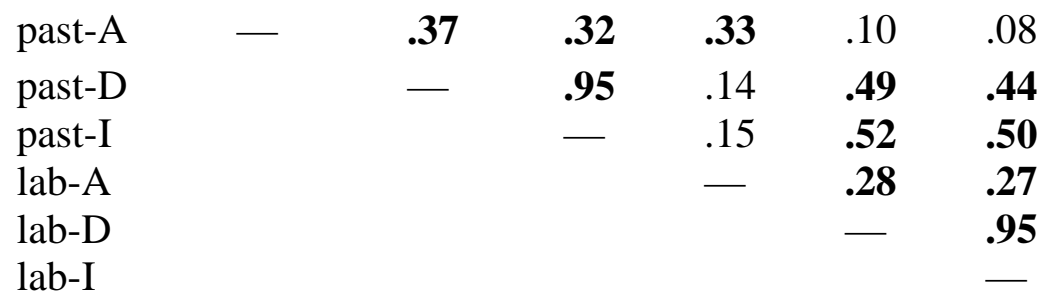

Note. Bolded values indicate $p<.01, \mathrm{~A}=$ assertive, $\mathrm{D}=$ diplomatic, $\mathrm{I}=$ immobile 
Table 3

Hierarchical Regression Analysis Examining the Relationship Between Past BRTT and Task Assertive BRTT

Task Assertive BRTT

Step and Predictor Variable

Step 1: acknowledgment and

B SE B

$\beta$

past barriers

African American (yes/no)

1.21

1.87

.07

.52

dev. revictimization (yes/no)

.71

$-2.38$

.89

.09

acknowledgment status

BRSA - past alcohol

$-.00$

$-.30$

.43

BRSA - past fear

$.30 \quad .27$

$-.00$

$.008 *$

BRSA - past judge

$-.06 \quad .07$

.11

.99

.23

$-.09$

.26

Step 2: past BRTT

past assertion

past diplomatic

$.18 \quad .07$

$-.45 \quad .39$

$.47 \quad .37$

$.07 \quad .29$

past immobile

$.37 \quad 48$

.48

.41

Note. $* p<.05, \mathrm{dev}=$ developmental, IIP $=$ inventory of interpersonal problems, BRSA $=$ barriers to responding to sexual aggression 


\section{Biographical Statements}

RaeAnn E. Anderson (PhD, University of Wisconsin-Milwaukee, 2015) is currently an Assistant Professor in Clinical Psychology at the University of North Dakota. She completed her postdoctoral training at Kent State University. Her research interests are understanding basic behavioral processes in sexual victimization and sexual perpetration in order to inform sexual assault risk reduction and prevention programs, respectively. She also conducts research on measurement issues in the assessment of sexual violence histories.

Shawn P. Cahill (PhD, SUNY Binghamton) is an Associate Professor of Psychology at the University of Wisconsin-Milwaukee. He is a member of the faculty in the clinical psychology doctoral program and conducts research on prolonged exposure therapy and interventions for sexual assault risk reduction.

Kristin E. Silver is a Ph.D. student in Counseling Psychology at The University of Akron. Broadly speaking, her research and clinical interests are at the intersection of mental health and human rights. She is particularly passionate about: women's sexual health, pleasure, and empowerment; the causes and consequences of trauma, along with empirically supported treatments for marginalized populations (e.g., human trafficking survivors); and intersectional feminist therapy and interventions. Methodologically speaking, her interests include mixed methods, treatment outcome research, prevention programming, and quantitative scale construction.

Douglas L. Delahanty (PhD, University of Pittsburgh) is a Professor of Psychology at Kent State University. He is a faculty member in experimental psychology and conducts research on the biological and psychological predictors of recovery from trauma in children and adults. 